\title{
ОСОБЕННОСТИ СЕЗОННОГО РАЗВИТИЯ И ДИНАМИКА УРОЖАЙНОСТИ ПЛОДОВ МАЛИНЫ САХАЛИНСКОЙ (RUВUS MATSUMURANUS LEVL. \& VANIOT) В ВЕРХОВЬЯХ КОЛЫМЫ (МАГАДАНСКАЯ ОБЛАСТЬ)
}

\author{
N.V. Sinelnikova, M.N. Pakhomov
}

\section{THE PECULIARITIES OF PHENOLOGY AND YIELD VARIATIONS OF SAKHALIN RASPBERRY FRUITS (RUBUS MATSUMURANUS LEVL. \& VANIOT) IN THE UPPER KOLYMA AREA (MAGADAN REGION)}

\begin{abstract}
Синельникова Надежда Вячеславовна - д-р биол. наук, вед. науч. сотр. лаб. ботаники Института биологических проблем Севера ДВО РАН, г. Магадан. E-mail: meks_mag@mail.ru

Пахомов Михаил Николаевич - ст. лаборантисследователь лаб. ботаники Института биологических проблем Севера ДВО РАН, г. Магадан. E-mail:meks_mag@mail.ru
\end{abstract}

Сезонное развитие и динамика урожая плодов малины сахалинской (Rubus matsumuranus Levl. \& Vaniot) изучались на западе Магаданской области в верховьях р. Кольма. Цель исследований - оценка изменчивости дат наступления френологических фраз малины сахалинской за период 2003-2019 г2. и выявление климатических фракторов, влияющих на колебания урожайности плодов. Задачи: обобщение данных фенологических наблюдений за популяциями малины и установление зависимости урожайности плодов от климатических показателей. Фенологические наблюдения проводятся с 2003 2. по настоящее время, урожайность оценивалась глазомерно по шкале КаппераФормозова. Метеорологические наблюдения на полевом стационаре ИБПС ДВО РАН ведутся с 1992 г. Описан ход сезонного развития малины (13 фенофраз) и особенности прохождения отдельных стадий. В течение 20032019 ге. произошли существенные изменения хода сезонного развития малины сахалинской. Установлены положительные тренды более раннего начала распускания почек и распускания листьев, что согласуется с возрастанием сумм среднесуточных температур выше $5{ }^{\circ} \mathrm{C}$ в начале вегетации. Статистически достоверной связи динамики урожайности плодов ни с одним из метеорологических показателей определить не удалось. Отмечается тенден-
Sinelnikova Nadezhda Vyacheslavovna - Dr. Biol. Sci., Leading Staff Scientist, Lab. of Botany, Institute of Biological Problems of the North, FEB RAS, Magadan.E-mail: meks_mag@mail.ru

Pakhomov Mikhail Nikolayevich - Senior Lab. Research Assistant, Lab. of Botany, Institute of Biological Problems of the North, FEB RAS, Magadan. E-mail:meks_mag@mail.ru

ция к снижению урожаев малины за последние 20 лет, обусловленная современными изменениями климата - увеличением частоты заморозков (ниже $\left.-2,5^{\circ} \mathrm{C}\right)$ в период цветения и ростом числа пасмурных дней в июне-июле.

Ключевые слова: дикорастущие ягодники, малина сахалинская, френология, Магаданская область.

Seasonal development and dynamics of the crop of fruits of Sakhalin raspberry (Rubus matsumuranus Levl. \& Vaniot) have been studied in the west of Magadan Region in headwaters of the Kolyma River. The purpose of the researches is the assessment of variability of dates of approach of phenological phases of Sakhalin raspberry during 2003-2019 and the identification of climatic factors influencing the fluctuations of productivity of fruits. The tasks are the synthesis of this phenological supervision over populations of raspberry and the establishment of the dependence of productivity of fruits on climatic indicators. Phenological observations have been made since 2003 up to the present; the productivity is estimated by eye with Kapper-Formozov's scale. Meteorological supervision on field hospital of IBPN FEB RAS have been conducted since 1992. The course of seasonal development of raspberry (13 phenohpases) and the features of passing of separate stages are described. During 2003-2019 there have been essen- 
tial changes of the course of seasonal development of Sakhalin raspberry. Positive trends of earlier beginning bud burst and leaf-out due to the increase of the sums of average daily temperatures above $5^{\circ} \mathrm{C}$ at the beginning of vegetation period are established. Statistically reliable communication of dynamics of productivity of fruits with one of meteorological indicators has not been defined. The tendency to decrease in crops of raspberry for previous 20 years caused by modern climate changes - the increase in frequency of frosts (below minus $2.5^{\circ} \mathrm{C}$ ) during blossoming and growth of the number of cloudy days in June-July is noted.

Keywords: wild berries, Sakhalin raspberry, phenology, Magadan Region.

Введение. На северо-востоке России дикорастущие ягоды традиционно используются в питании населения. В последние десятилетия интерес к изучению природных популяций неуклонно возрастает, а некоторые виды успешно вводятся в культуру [1]. К сожалению, современные изменения климата в значительной степени негативно влияют на продуктивность ягодных растений [2], что вызывает необходимость всестороннего изучения особенностей их сезонного развития. С 1992 г. и по настоящее время фенологический мониторинг дикорастущих ягодников ведется на Оротукском полевом стационаре лаборатории ботаники ИБПС ДВО РАН в верховьях р. Колыма (62 $03^{\prime}$ с.ш., 148039' в.д.), расположенном в Тенькинском районе Магаданской области в 11 км к юго-западу от с. Оротук [3].

Малина сахалинская (Rubus matsumuranus Levl. \& Vaniot) - сибирско-североамериканский бореальный вид, летнезеленый кустарник 0,51,5 м высотой с шиповато-щетинистыми побегами. Листья тройчатые, снизу по жилкам щетинистые. Ежегодно отрастают вегетативные побеги замещения, которые одревесневают к осени и на следующий год ветвятся, образуя пазушные соцветия с 4-5 цветками. После плодоношения побеги отмирают. Цветет в июне, плоды созревают в первой декаде августа. Ценное пищевое и лекарственное растение, хороший медонос. В медицине используются плоды, листья, цветки и корни. Сушеные плоды применяют в научной медицине, а листья и цветки - в медицине народов Севера [4]. Популяции отличаются значительным полиморфизмом и представляют большой интерес для селекции и интродукции [5]. Малина сахалинская распространена к востоку от Енисея, кроме Арктики, на
Камчатке и Сахалине, достигая на Чукотке границы леса в бассейне р. Анадырь. Встречается как в подгольцовом поясе, так и в зоне лиственничных редколесий на сухих южных склонах, вырубках, каменистых россыпях, обрывах и гарях, где предпочитает участки с разреженным древесным пологом. Из-за труднодоступности продуктивных участков запасы плодов малины в континентальных районах Магаданской области используются недостаточно. На приусадебных участках встречаются растения, пересаженные из природных популяций, но обычно их урожайность невысока.

Цель работы. Оценка динамики дат наступления фенологических фаз малины сахалинской за период 2003-2019 гг. и определение климатических факторов, влияющих на колебания урожайности плодов.

Задачи исследований: обобщение данных фенологических наблюдений за популяциями малины сахалинской и статистический анализ зависимости динамики урожайности плодов от метеорологических показателей.

Материалы и методы. Район исследований расположен на северо-западе Магаданской области в верховьях Колымы. Зональная растительность представлена лиственничными редколесьями с подлеском из кедрового стланика (Pinuspumila Regl.). Климат района - переходноконтинентальный. Зима умеренно суровая, продолжительностью в среднем 220 дней (средняя температура января $\left.-38,3^{\circ} \mathrm{C}\right)$. Лето умеренно теплое, средняя температура июля $15,1{ }^{\circ} \mathrm{C}$. Безморозный период в $30 \%$ лет отсутствует, повсеместно распространена многолетняя мерзлота. Годовое количество осадков составляет в среднем 307 мм. Объектом исследований служили популяции малины сахалинской, расположенные на юго-восточных склонах долины Колымы.

Фенологические наблюдения проводятся по общепринятым методикам с 2003 г. и по настоящее время, урожайность оценивалась глазомерно по шкале Каппера-Формозова [6]. Метеорологические наблюдения по программе метеопоста ведутся на стационаре с 1992 г., статистическая обработка метеорологических и фенологических данных выполнена с помощью программы STATISTICA 8,0, колебания средних фенодат анализировались по среднему квадратическому отклонению (S). Даты наступления основных френологических фаз в таблице приво- 
дятся в соответствии с международной кодировкой фенологических фаз растений - ВВСН [7].

Результаты и их обсуждение. Основным фактором, влияющим на прохождение фаз сезонного развития малины, служат температурные показатели, прежде всего суммы среднесуточных температур выше 0 и $5{ }^{\circ} \mathrm{C}$. Продолжительность вегетационного периода составляет $100,2 \pm 2,8$ дней. Снежный покров на участках наблюдений разрушается 20.04-5.05, после чего почва постепенно оттаивает и прогревается. Вегетация малины начинается в конце первой декады мая с набухания почек, которое происходит при накоплении $\sum \mathrm{T} \geq 5^{\circ} \mathrm{C}$ в $20,4 \pm 3,3^{\circ} \mathrm{C}$ (табл.). В течение 10-12 дней почки зеленеют и распускаются. В генеративном цикле происходит отрастание боковых веточек, на которых развиваются бутоны, и к 20-25 июня малина начинает цвести при накоплении $\Sigma \mathrm{T} \geq 5^{\circ} \mathrm{C}$ в $357,1 \pm 12,1^{\circ} \mathrm{C}$. Цветение продолжается 20-25 дней, причем в одном соцветии могут одновременно находиться как начинающие окрашиваться бутоны, так и полностью раскрывшиеся цветки. Плоды растут в течение месяца и в последней декаде июля начинают созревать. Массовое созревание плодов проходит в первых числах августа, после чего они почти сразу осыпаются, поэтому оптимальные сроки сбора - от 31 июля до 10 августа. В вегетативном цикле распуска- ние листьев происходит в среднем 4 июня, а через 10-12 дней листья малины полностью развертываются. Одновременно начинают расти побеги замещения, развитие которых заканчивается к середине июля. Сроки наступления расцвечивания и опада листьев существенно зависят от $\Sigma \mathrm{T} \geq 5^{\circ} \mathrm{C}$, а после листопада отплодоносившие побеги усыхают. Ранее было установлено, что скорость прохождения большей части фенофаз и длительность основных межфазных периодов (феноамплитуды) существенно зависят от сезонного хода накопления положительных среднесуточных температур [3]. Анализ дат наступления фенофаз малины показал, что фазы генеративного цикла не показывают существенных трендов за период наблюдений. Напротив, некоторые фазы вегетативного цикла демонстрируют существенные положительные тренды, хорошо согласующиеся с увеличением сумм положительных температур в 2003-2019 гг., которое наблюдается во второй половине мая - начале июня. Распускание почек и начало распускания листьев сейчас происходит на 8-12 дней ранее, чем в начале 2000-х годов, но это не сказывается на сроках прохождения дальнейших стадий, поскольку во второй половине июня существенного потепления не наблюдается.

\section{Даты наступления фенологических фаз малины сахалинской и параметры линейных трендов (2003-2019)}

\begin{tabular}{|c|c|c|c|c|c|c|c|c|}
\hline \multirow[t]{2}{*}{ Фенофраза } & \multicolumn{4}{|c|}{ Даты наступления } & \multicolumn{2}{|c|}{$\begin{array}{l}\text { Параметры } \\
\text { тренда }\end{array}$} & \multirow{2}{*}{ 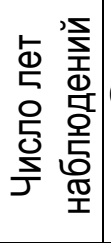 } & \multirow{2}{*}{$\begin{array}{c}\text { Номер } \\
\text { стадии по } \\
\text { шкале } \\
\text { ВВСН }\end{array}$} \\
\hline & Ранняя & Поздняя & Средняя & $\pm S E$ & Наклон & $\mathrm{R}^{2}, \%$ & & \\
\hline 1 & 2 & 3 & 4 & 5 & 6 & 7 & 8 & 9 \\
\hline Набухание почек & 1.05 & 20.05 & 10.05 & 1,5 & $-0,33$ & 7,9 & 18 & 01 \\
\hline Распускание почек & 10.05 & 2.06 & 21.05 & 1,6 & $-0,79$ & $39,6^{*}$ & 17 & 09 \\
\hline Начало распускания листьев & 25.05 & 12.06 & 4.06 & 1,5 & $-0,71$ & $38,5^{*}$ & 17 & 11 \\
\hline Полное облиствение & 6.06 & 1.07 & 16.06 & 1,7 & $-0,03$ & 0,0 & 18 & 19 \\
\hline Бутонизация & 11.06 & 6.07 & 20.06 & 1,7 & $-0,21$ & 2,6 & 18 & 59 \\
\hline Начало цветения & 14.06 & 15.07 & 25.06 & 1,8 & $-0,44$ & 9,0 & 17 & 61 \\
\hline Массовое цветение & 10.06 & 2.07 & 19.06 & 1,5 & $-0,31$ & 7,3 & 18 & 65 \\
\hline Завязывание плодов & 24.06 & 23.07 & 5.07 & 1,8 & $-0,19$ & 2,0 & 18 & 71 \\
\hline Образование плодов & 3.07 & 13.08 & 19.07 & 2,1 & $-0,24$ & 2,1 & 18 & 79 \\
\hline Массовое созревание плодов & 20.07 & 14.08 & 30.07 & 1,5 & $-0,24$ & 4,3 & 18 & 89 \\
\hline $\begin{array}{l}\text { Начало расцвечивания } \\
\text { листьев }\end{array}$ & 5.08 & 25.08 & 14.08 & 1,2 & $-0,08$ & 0,7 & 18 & 92 \\
\hline
\end{tabular}




\begin{tabular}{|l|c|c|c|c|c|c|c|c|}
\hline \multicolumn{1}{|c|}{1} & 2 & 3 & 4 & 5 & 6 & 7 & 8 & 9 \\
\hline $\begin{array}{l}\text { Полное расцвечивание } \\
\text { листьев }\end{array}$ & 12.08 & 7.09 & 25.08 & 1,4 & $-0,06$ & 0,3 & 18 & 95 \\
\hline Начало листопада & 18.08 & 14.09 & 1.09 & 1,7 & $-0,57$ & 18,7 & 18 & 93 \\
\hline
\end{tabular}

${ }^{*}$ Статистически достоверные тренды.

По литературным данным, среднегодовая урожайность насаждений малины на Дальнем Востоке составляет 50-100 кг/га (в среднем 80) [8]. Вес 100 ягод в изученных популяциях колеблется в различные годы от 40 до 49 г. Цвет плодов преимущественно красный, но в 2001 г. обнаружена форма со светло-розовыми плодами, которые отличаются более крупными размерами и высокими вкусовыми качествами. По нашим наблюдениям, основной урожай формируется из 2-3 цветков, распустившихся первыми, поэтому эфффективен первый сбор ягод, реже - второй сбор через 4-5 дней.

Урожайность плодов малины подвержена значительным колебаниям (рис.), причем в последнее десятилетие наблюдается тенденция к еe снижению, обусловленная современными изменениями климата. Для анализа динамики урожайности привлекали большую группу климатических показателей: суммы температур воздуха выше 0,5 и $10{ }^{\circ} \mathrm{C}$, среднедекадные и среднемесячные температуры теплого периода (май-сентябрь), а также декадные и месячные показатели количества осадков. Статистически достоверной связи урожайности плодов ни с одним из этих параметров обнаружить не удалось. Замечено, что насекомые-опылители практически не посещают цветков ягодных растений в пасмурную погоду [9], поэтому статистически достоверный рост числа пасмурных дней в июне-июле, отмеченный в 1992-2019 гг., вероятно, оказывает влияние на снижение урожаев. Наиболее значимым фактором оказались заморозки ниже $-2,5^{\circ} \mathrm{C}$ в период цветения, частота которых за последние 20 лет возросла на $60 \%$. Например, 18 июня 2003 г. и 23 июня 2006 г. в разгар цветения малины наблюдались заморозки в -6,3 и -5,8 ${ }^{\circ} \mathrm{C}$ соответственно, полностью повредившие цветки. В 2010-2013 гг. заморозки в $-3 \ldots-4{ }^{\circ} \mathrm{C}$ приходились на начало цветения. Метеорологические показатели года, предшествующего плодоношению, также сказываются на урожайности малины. Недостаточное количество осадков в июне вызывает слабое развитие побегов замещения, которые рано прекращают рост и имеют небольшое число листьев, что наблюдалось в 2010, 2012 и 2016 гг. Связь урожаев с накоплением влаги в конце вегетационного периода предыдущего года не установлена.

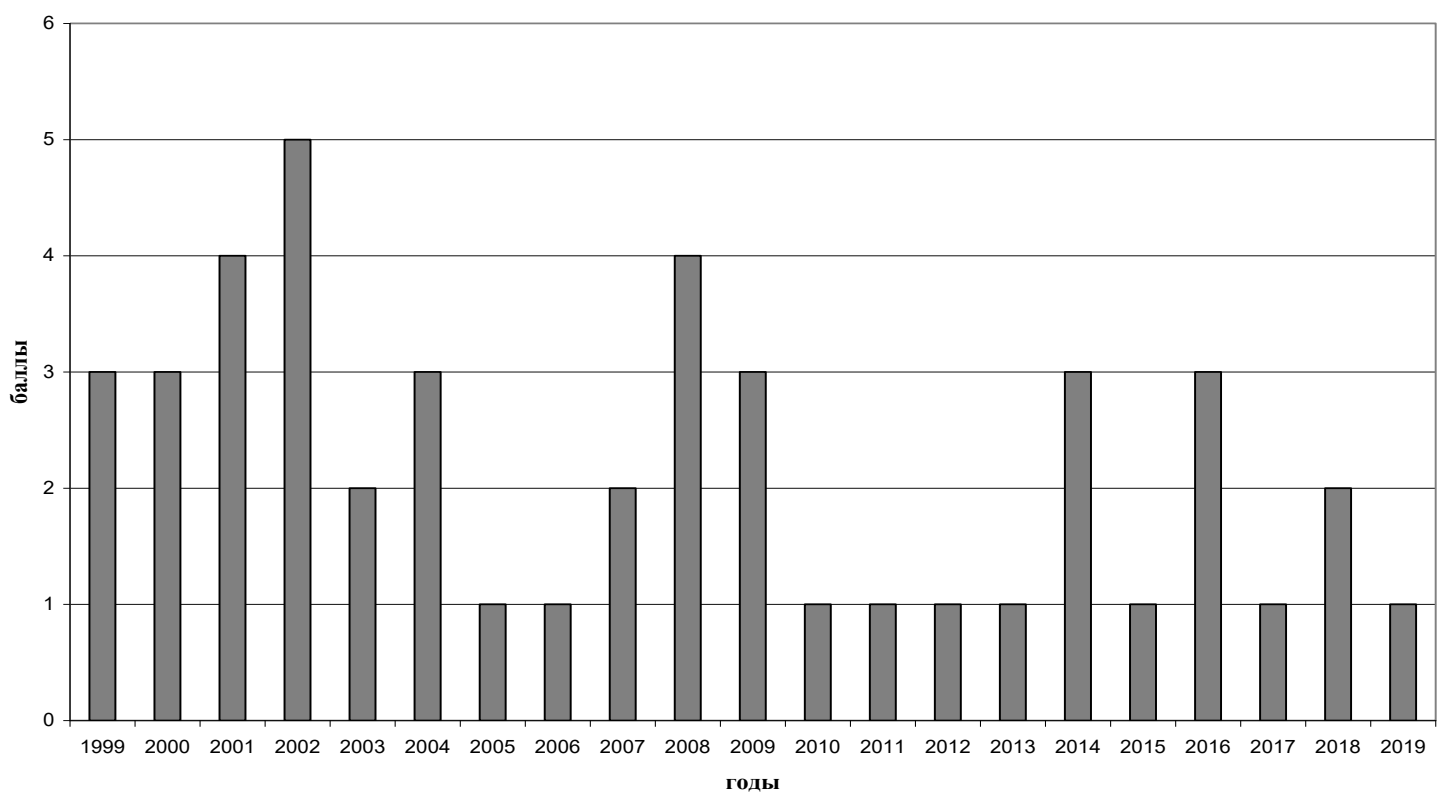

Динамика урожайности плодов малины сахалинской (1999-2019) 
Выводы. В течение 2003-2019 гг. произошли существенные изменения хода сезонного развития малины сахалинской, связанные с климатическими показателями вегетационного периода. Наблюдаются положительные тренды более раннего начала распускания почек и распускания листьев, что согласуется с постепенным возрастанием сумм среднесуточных температур выше $5{ }^{\circ} \mathrm{C}$ в начале вегетации. Существует тенденция к снижению урожаев малины, обусловленная увеличением частоты заморозков (ниже $2,5^{\circ} \mathrm{C}$ ) в период цветения и ростом числа пасмурных дней, в которые цветки не посещаются насекомыми-опылителями.

\section{Литература}

1. Коробкова Т.С. Изменчивость морфологических признаков голубики топяной (Vaccinium uliginosum L.) в Центральной и Южной Якутии // Вестник КрасГАУ. - 2016. № 10. - C. 16-21.

2. Синельникова Н.В., Пахомов М.Н. Ресурсы дикорастущих ягодников в верховьях р. Колыма // Вестник Северо-Восточного научного центра ДВО РАН. - 2011. - № 2. - С. 87-99.

3. Синельникова Н.В., Пахомов М.Н. Сезонная жизнь природы Верхней Колымы. - М.: KMК, 2015. - 329 c.

4. Атлас лекарственных растений Якутии. Т. 1. Лекарственные растения, используемые в научной медицине. - Якутск, 2003. $194 \mathrm{C}$.

5. Коропачинский И.Ю., Встовская Т.Н. Древесные растения Азиатской России. - Новосибирск: ГЕО, 2002. - 708 с.

6. Методы изучения лесных сообществ / под ред. В.Т. Ярмишко. - СПб., 2002. - 240 с.

7. Growth Stages of Mono-and Dicotyledonous plants / ed. U. Meier. BBCH Monograph. BlackwellWiss. Verlag-Berlin-Vien, 1997. $622 \mathrm{p}$.

8. Шемякина А.В. Малина сахалинская на российском Дальнем Востоке (видовой со- став, распространение, ресурсы) // Плодоводство, семеноводство, интродукция древесных растений. - 2018. - Т. 21. - С. 289291.

9. Косицын В.Н. Морошка: биология, ресурсный потенциал, введение в культуру. - М., 2001. - 130 c.

\section{Literatura}

1. Korobkova T.S. Izmenchivost' morfologicheskih priznakov golubiki topyanoj (Vaccinium uliginosum L.) v Central'noj i Yuzhnoj Yakutii // Vestnik KrasGAU. - 2016. - № 10. - C. 16-21.

2. Sinel'nikova N.V., Pahomov M.N. Resursy dikorastushchih yagodnikov $\mathrm{V}$ verhov'yah r. Kolyma // Vestnik Severo-Vostochnogo nauchnogo centra DVO RAN. - 2011. - № 2. - S. 87-99.

3. Sinel'nikova N.V., Pahomov M.N. Sezonnaya zhizn' prirody Verhnej Kolymy. - M.: KMK, 2015. - $329 \mathrm{~s}$.

4. Atlas lekarstvennyh rastenij Yakutii. T. 1. Lekarstvennye rasteniya, ispol'zuemye $\mathrm{v}$ nauchnoj medicine. - Yakutsk, 2003. - $194 \mathrm{~s}$.

5. Koropachinskij I.Yu., Vstovskaya T.N. Drevesnye rasteniya Aziatskoj Rossii. - Novosibirsk: GEO, 2002. - $708 \mathrm{~s}$.

6. Metody izucheniya lesnyh soobshchestv / pod red. V.T. YArmishko. - SPb., 2002. - 240 s.

7. Growth Stages of Mono-and Dicotyledonous plants / ed. U. Meier. BBCH Monograph. BlackwellWiss. Verlag-Berlin-Vien, 1997. $622 p$.

8. Shemyakina A.V. Malina sahalinskaya na rossijskom Dal'nem Vostoke (vidovoj sostav, rasprostranenie, resursy) // Plodovodstvo, semenovodstvo, introdukciya drevesnyh rastenij. - 2018. - T. 21. - S. 289-291.

9. Kosicyn V.N. Moroshka: biologiya, resursnyj potencial, vvedenie v kul'turu. - M., 2001. $130 \mathrm{~s}$. 